International Journal of Environment, Agriculture and Biotechnology
Vol-6, Issue-6; Nov-Dec, 2021
Journal Home Page Available: $\underline{\text { https://ijeab.com/ }}$
Journal DOI: $10.22161 /$ ijeab

\title{
A comparison of bacterial variability across biogeographic regions based on PGPR
}

\author{
Sampa Biswas, Arghya Nath, Rajat Pal*
}

Department of Microbiology and Biotechnology, Sister Nivedita University, India

*Corresponding Author

Received: 26 Sep 2021; Received in revised form: 01 Nov 2021; Accepted: 12 Nov 2021; Available online: 20 Nov 2021

(C2021 The Author(s). Published by Infogain Publication. This is an open access article under the CC BY license

(https://creativecommons.org/licenses/by/4.0/).

\begin{abstract}
Plants are sessile organisms that experience abiotic stresses like sediment salinity, drought, and extreme temperatures. In light of our growing population and increasing demand for better nutrients and commercial quality foods, optimizing the use of our natural resources is essential to ensuring food security.Enhancing PGPR using modern tools and techniques of biotechnology can greatly contribute to achieving sustainable agriculture, by improving soil fertility, plant tolerance, crop productivity, and maintaining a balanced nutrient cycling. Plant rhizospheres could contribute to the development of robust plant growth-promoting (PGP) activities and stress tolerance capabilities under drought conditions. They enhance the adaptation of plants for different desertification environments because they are diverse and functionally redundant (PGPR). In addition to soil properties and plant species, there are a variety of biotic and abiotic factors that influence their composition and abundance. In this review article, we learn how Bacterial diversity is influenced by soil environment and geophysical conditions.
\end{abstract}

Keywords-Endosphere, Halotolerant, Microniches, PGPR, Rhizosphere, Xerophytic Microflora.

\section{INTRODUCTION}

Soil environment and geophysical conditions have a direct impact on bacterial diversity. The soil is composed of microinches with heterogeneous physical and chemical properties across a wide range of scales. Since bacteria live in small pockets within a niche, the properties of their immediate environment rather than the soil's mean properties influence the survival of their local community. Space heterogeneity has been shown to result in lower survival rates in local communities due to the heterogeneity of the bacterial communities on $<1 \mathrm{~cm}$ [1]. Abiotic factors such as soil physicochemical properties and geographical location are important factors that shape bacterial community abundance and diversity. The type and location of soil, as well as the plant species in an area, significantly change the structure of bacterial communities. The functional profiles of soil bacterial communities were influenced by both the location of the soil and the plants in the soil. Researchers have found that soil and plants play a major role in shaping rhizosphere microbiota's composition [2]. In rhizospheres, different soil properties such as $\mathrm{pH}$, concentrations of phosphorus and potassium, as well as concentrations of other mineral nutrients, affect the composition of the bacterial communities differently [3].

The PGPR bacteria are beneficial bacteria that colonize the roots of plants and enhance their growth through a variety of mechanisms [4]. These bacteria colonize the roots of plants and boost their growth in a variety of ways. Take steps to control insect and disease damage. Either directly or indirectly assist plants in growing. Reducing agricultural reliance on hazardous chemicals. Enhancing soil fertility by releasing nutrients. They affect plant growth in several ways, including direct mechanisms such as nutrition and growth regulation, as well as indirect mechanisms related to their ability to biocontrol [5]. A key tool for boosting sustainable agriculture, PGPR has gained popularity over the last few decades. PGPRs can affect plant growth either indirectly or directly. Direct growth promotion by PGPR involves giving a plant a bacterium-produced compound, such as phytohormones, or encouraging the plant to take up nutrients from the environment [6]. By inhibiting the negative effects of phytopathogenic organisms, PGPR 
indirectly promotes plant growth. By doing so, antagonistic substances are produced or resistance is created against pathogens [6].

Rhizobacteria associated with plants are effective at raising plant tolerance to stress [7][8][9]named this phenotypic tolerance to abiotic stress "Induced General Tolerance" to describe plant responses to PGPR-induced abiotic stress. Based on their proximity and intimacy to roots, Rhizobacteria are divided into (i) soil-dwelling bacteria, which utilize roots' metabolites for carbon and nitrogen, (ii) rhizoplane- colonizing bacteria, (iii) bacteria that reside inside cortical cells, and (iv) bacteria living within specialized root structures. As the distance between the root and the plant changes, so does the association of plant growth-promoting bacteria. Extracellular PGPR (ePGPR) and intracellular PGPR (iPGPR) make up the vast majority of PGPR [10].PGPR (iPGPR) bacteria live inside plant cells and produce nodules. They are located in these specialized structural elements. PGPR (ePGPR) bacteria don't produce nodules but stimulate plant growth through the production of signal compounds. The species of Rhizobium, Mesorhizobium,Bradyrhizobium, Allorhizobium, and Frankia are examples of these. For higher plants, these fix atmospheric nitrogen [11].Based on their level of association with roots, ePGPR can be classified into three types: bacteria living near but not in contact with roots; bacteria colonizing the surface of roots; and bacteria growing between the cells of root cortex [12]. Azotobacter, Caulobacter, Azospirillum, Bacillus, Erwinia, Chromobacterium, Agrobacterium, Erwinia, Flavobacterium, Arthrobacter, Micrococcus, Pseudomonas and Burkholderia are some examples of ePGPRs. There is much greater diversity in host plant proximity, infection mode, and, most significantly, plant effect on ePGPR associations, compared to iPGPR[13].

Communication and environmental sensing are carried out by both beneficial and pathogenic bacteria using QS. It consists of a series of gene-regulated molecules known as autoinducers that act on bacteria at the gene level [14]. To maximize their population size and fitness, bacteria release AIs into the environment to assess their surroundings and adapt their gene expression accordingly. AHL, for example, is one of the many wellstudied artificial ions produced by Gram-negative bacteria, whereas cyclic peptides are prevalent among Grampositive bacteria [15].Furthermore, QS is involved in several physiological behaviours such as symbiosis, virulence, antibiotic production, conjugation, competence, sporulation, and biofilm formation [16]. PGPRs also communicate with higher organisms, such as plants, using QS, whether they belong to the same species or not. As it turns out, plant-microbe communication is now evidently dependent on QS communication for microbial interactions at the rhizosphere [17].Evolutionary adaptations of plants have introduced an array of ways for them to respond to QS, such as sensing and responding to bacterial QS signals, and producing substances that mimic AHL and can impact QS in the plant-associated bacterial community. Numerous studies also reveal that the rhizosphere harbours more AHL producing bacteria than the bulk soil, and that these AHL molecules are capable of acting as inter-kingdom signalling molecules [17][18]. When rhizobacteria form closer associations inside the roots of plants, they are called endophytes. The term is defined as "bacteria that can be isolated from surface-disinfected plant tissue, or that can be extracted from the plant itself without causing visible harm to the plant" [19].There are several types of endophytes, such as rhizobialnodulating bacteria and nitrogen fixers [20].

\section{RHIZOSPERE}

Life's terrain consists of the elements of an ecosystem that cannot be seen by the naked eye, such as soil or water. In soils, rhizosphere is likely the primary site of bacterial activity. "Rhizosphere" originates from the Greek words "rhiza" (root) and "soi" (ground). It can also be referred to as the root zone, soil zone, or hydrological region. PGPRS colonizes plant roots by inhabiting root tissues, around roots, and on the rhizoplane (root surface) [6].Rhizospheres were first described by German scientist Lorenz Hiltner (1904) as "areas of soil next to legume roots where bacteria thrive.". Therefore, it is a nutrient-rich area of soil directly surrounding roots of plants. Unlike other regions, this one has no distinct edges; it is influenced by compounds released by the roots and microbial life that feeds upon them. Its varied and dense flora makes it a highly dynamic region. By observing the composition and pattern of root exudates, we can gain insight into microbial activity and population proportions. Rhizosphere interactions affect root growth and function, ultimately resulting in changes to the plant's growth. Each plant species hosts a unique PGPR community[21].

\section{PGPR IN DESSERTS: BACTERIAL COMMUNITY SHAPING FORESTS IN DESERT PLANTS}

Deserts are dynamic, heterogeneous habitats that take up one third of the planet. A desert plant's adaptation to the desert environment is also determined by the microbial communities that colonize and inhabit its surrounding soils [22]. It is extremely hard for microbes to 
thrive in deserts[23].Around the world, climates vary widely, but all are characterized by extreme temperatures, desiccation, soil salinity, minimal amounts of nutrients, and high levels of ultraviolet radiation during the summer. Xerophytic microflora flourishes in environments of constant water stress over an extended period of time. Due to the harshness of desert environments for so long, desert plants were forced to develop unique structures, including specialized leaves and stems, to adapt to the frequent stress conditions associated with deserts [24]. It is observed that drought affects plants' water potential [25] as well as soil nutrient availability and distribution [26] also contributing to an increase in reactive oxygen species (ROS) [27]. An excessive amount of ROS can cause lipid peroxidation, which harms plants in morphology and physiological functions [28].The plants use an array of antioxidant enzymes to keep them healthy, including superoxide dismutase (SOD), peroxidase (POD), catalase (CAT) and ascorbate peroxidase, and non-enzymatic antioxidants like glutathione and proline, which plants use to scavenge ROS and prevent membrane damage [29][30][31]. Bacteria react differently to drought stress at different organizational levels depending on the intensity of the stress, period, species, and stage of growth. The PGPR could be beneficial for developing strategies to facilitate the conservation of plant water. The PGPR isolated from desert soils has evolved well to deal with extreme environmental factors like salinity and heat, enabling stress response genes to promote plant growth and enhance soil fertility [32 [33][34][35][36].

Although these pioneer desert plants were subjected to extreme conditions, their rhizospheres contained a rich diversity of bacteria. The composition of rhizosphere bacterial communities is influenced by abiotic factors such as soil type and composition, location, and soil properties. In similar geographical locations, the soil, rhizosphere, phyllosphere and associated bacterial communities are similar, whereas plants in distant geographic locations with distinct soil properties have a different soil bacterial community and have different associated bacterial communities. Furthermore, plant host genotyping has an effect on the community of bacteria in the Endosphere. There are a variety of bacterial communities in desert plants, but two major phyla are mainly dominant: Proteobacteria and Actinobacteria. Proteobacteria have a wide range of adaptation capabilities to a variety of environmental lifestyles, including nitrogenfixing plant symbionts such as Rhizobium, Mesorhizobium, and Sinorhizobium[37].The Actinobacteria have shown impressive versatility in their ability to grow under extreme conditions including salinity, low $\mathrm{pH}$, low water availability, high radiation, and pressure, they include several diverse species (including alkalophiles, acidotolerants, thermotolerant, and halotolerant) [38].

There are certain features of desert plants that make them dependent on bacterial communities, such as high expression of genes related to dormancy and osmoregulation, and lower expression of genes related to nutrient cycling and catabolisms. Root exudates, plant species, genotypes, and plant compartments all determine the diversity of bacteria in the plant Endosphere [21] [39][40][41] [42].Plants mediated by PGPR are known to withstand drought stress in several ways, from producing exopolysaccharides (EPS) to 1-aminocyclopropane-1carboxylic acid (ACC) deaminase to reduce ethylene production [43]. PGPR strains can reduce drought-induced oxidative damage to plants by increasing antioxidant enzyme activity [44]. A PGPR strain Mitsuaria and a PGPR strain Burkholderia produced ACC deaminase and EPS that improved the root system of Arabidopsis by increasing proline content and antioxidant activity and decreasing malondialdehyde levels [45].The strains of Variovorax paradoxus RAA3, Pseudomonas palleroniana DPB16, and Pseudomonas sp. are capable of relieving wheat from drought stress. The UW4 strain [46]was isolated from pepper by Bacillus licheniformis K11 [47]. Glycyrrhiza uralensis grew better under drought stress when Bacillus pumilus modified antioxidant levels [30]. EPS is beneficial for plant survival during drought conditions [48]. The EPS-producing strains of Proteus penneri (Ep1), Pseudomonas aeruginosa (Pa2), and Alcaligenes faecalis (AF3) have previously been isolated [49]. There are abundant and diverse microbial communities in desert soils across the world, among which the four most universal phyla are Actinobacteria, Proteobacteria, Bacteroidetes, andCyanobacteria[50].

\section{IMPACT OF AQATIC PGPR}

Due to the unique nature of the underwater life history, the competition for abiotic resources, like light availability, is more intense in the fresh water ecosystem. Additionally, freshwater ecosystems are typically biologically inaccessible. Rehabilitating macrophyte species and communities is more challenging than rehabilitating terrestrial plants. Aquatic plants, due to their adaptability to aquatic environments and rapid reproduction rate, offer good potential for restoring habitats and removing special pollutants, like pesticides and toxic metals [51] [52]. A PGPR can increase aquatic plant growth by dissolving potassium, phosphorus, releasing hormones such as Cytokinin's and Indole-3acetic acid (IAA), generating siderophores and 1aminocyclopropane-1-carboxylatedeaminases 
[53], thereby enhancing plants' resistance to environmental stresses [54].

The PGPR strains can enhance the recovery of submerged plants in organically rich sediment [55]. In many parts of the world, water ecosystems are experiencing deterioration in water quality and ecological structure [56].After a decrease in water nutrition level, macrophytes usually take decades to adjust to the new environment [57]. The presence of organic sediment in lakes negatively impacts their ecological restoration because it acts as a stressor for macrophyte growth. It has been demonstrated that sediment anoxia inhibits the germination and sprouting of submerged macrophytes during restoration [58], and there are numerous issues associated with organic enrichment in water. An anoxic degradation pathway causes oxygen exhaustion and accumulation of potentially phytotoxic compounds, which causes benthic vegetation to decline [59]. The high organic matter content of fertile sediments leads to decreases in aquatic plant biomass. Furthermore, excessive organic matter content can generate reductive sapropel, which threatens aquatic plants' survival [60].Phoridobacteria (PGPR) were screened from the rhizosphere of submerged macrophytes and selected for their ability to promote Vallisneria natans under the high preponderance of sediment organic matter [55].

\section{IMPACT OF HALOPHYTES}

Agricultural sustainability is seriously threatened by soil salinity. The salt content in soils is one of the major abiotic stressors known to affect arid and semi-arid regions, and this leads to significant losses in agriculture productivity.2009 determined that increases in salinity negatively affect the growth-promoting characteristics of PGPRs[61]. Therefore, using halotolerant PGPRs that are selected for high salt tolerance along with efficiency in expressing PGPR traits would allow crops to be grown successfully in environments with natural or induced salinity [62].

Salt-tolerant plants such as halophytes adapt to salt-contaminated environments and can survive at salinities as high as $1 \mathrm{M} \mathrm{NaCl}$ [63] [64]. Halophytic plants have a lot of salt-tolerant rhizobacteria in the rhizosphere, which is beneficial to crops at a low level of salinity stress [65] [66] [67]. Rhizobacteria that live in high saline environments have evolved many strategies to survive, one of these strategies is the ability to accumulate compatible osmolytes, maintaining a balance between the forces of diffusion and growth [68] [69]. These microorganisms exhibit multiple biochemical and physiological stress- related traits that facilitate plant immunity to salt stress under lower salinity levels [69] [70] [71] [72].

Halotolerant may grow in environments varying from one to thirty-third $\mathrm{NaCl}$, as well as at intervals without $\mathrm{NaCl}$ [73] [74]. Under low water potential owing to salt stress, they are thus found at intervals in the rhizosphere of halophytes [61] [75]. The plant growthpromoting bacteria Moneron pumilus, Mendocina spp., Arthrobacter spp., Halomonas spp., and Nitrinicolacisaponensishave features such as phosphorus (P) solubilization, in addition to producing ACC deaminase, IAA, and siderophores. These traits are referred to as PGP traits because they allow plants to produce under limiting conditions, stimulate plant growth by serving as a phytohormone (IAA), provide metal to the plant through chelation (siderophores), and release a precursor to the plant stress hormone (ACC deaminase).

The endogenous phytohormone is regulated by PGPRs [76][77][78] and assists the signalling phytohormone (GA) in inhibiting the growth of plants under stress [79][80] that affect biological processes and elongation, hypocotyls, stem growth, leaf and root part size $[80][81][82]$.

\section{TROPICAL MANGROVE ECOSYSTEM NEED TO BE MAINTAINED BY MAINTAINING MICROBIAL COMMUNITY DYNAMICS:}

The mangrove forest is considered to be one of the most productive and biologically diverse wetlands on Earth, constituting an important natural reserve. There are currently fewer than $50 \%$ remaining, with half of it being degraded. Due to the deforestation of mangroves in many parts of the world, fish resources are dwindling, water supplies are being contaminated, and coastal erosion and salinization are rampant. Plants can use the nitrogen, phosphorus, and other nutrients being generated by the highly diverse and productive microbial community in tropical and subtropical mangrove ecosystems. Despite having a high organic matter content, mangrove ecosystems generally lack nutrient levels, especially nitrogen and phosphorus [83][84][85]. Mangrove ecosystems are heavily dependent on microbial modification (bacteria and fungi) for nutrient cycling [85 [86][87]. The world's mangrove ecosystems are important natural resources that require protection [88].A greater effort needs to be made to protect high-quality or primary mangrove sites. Mangrove rhizosphere bacteria can be used to enhance reforestation in Tamil Nadu's Pichavaram mangrove wetland, a habitat dominant in Rhizophora and Avicennia species. 
There are some bacterial strains isolated from the root rhizosphere of mangrove plants that are useful as PGPBs and could be used to promote plant growth in programs of reforestation, or in the creation of mangrove wetlands in coastal lagoons. The inoculation of black mangrove plantlets with $M$. chthonoplastes caused roots to colonize rapidly, increasing nitrogen fixation [89] as well as nitrogen accumulation [90]. When black mangrove seedlings were inoculated with a mixture of two bacteria, nitrogen was incorporated into the leaves twice as much and leaves developed more rapidly [91]. Mangrove roots may contain bacteria that can be used as PGPB to improve the establishment and enhance the growth of coastal mangrove seedlings.

Nitrogen fixation occurs frequently in mangroves. Nitrogen was fixated at high rates in association with dead and decomposing leaves, pneumatophores (air roots), the root rhizosphere, tree bark, Cyanobacterial mats that covered surface sediments as well as the sediments themselves [84][89][92][93][94][95][96][97][98][99].Vari ous mangrove species were found to contain nitrogenfixing bacteria grouped into the genera Azospirillum, Azotobacter, Rhizobium, Clostridium, and Klebsiella [83][100].

\section{BACTERIA ASSOCIATED WITH FOREST SOILS}

Forest soil bacteria are an important part of the soil microbial community, though they are understudied.In forest ecosystems, bacteria perform diverse ecological functions such as organic matter decomposition, mycorrhizal symbiosis regulation, and participation in the $\mathrm{N}$ cycle. The major natural agents responsible for $\mathrm{N}$ fixation in forest ecosystems are bacteria [101] as well as other processes, such as mineral weathering, that cause inorganic nutrients to be released [102]. A forest ecosystem provides many habitats for bacteria, including soils, plant tissues, streams, rocks, etc., however, soils and litter, which are particularly rich in bacteria, are predominant on the forest floor [103]. According to most studies, Acidobacteria, Actinobacteria, Proteobacteria, Bacteroidetes, and Firmicutes are abundant in soil [104]. Soil $\mathrm{pH}$ is one of the most important drivers in determining the composition of bacterial communities. in addition to ph. other components such as the organic matter content, nutrient availability, climate conditions, and biotic interactions (especially the influence of vegetation), influence bacterial community composition [104].

Two-thirds of the earth's $\mathrm{C}$ is stored in forest soils [105]. A great deal of the global carbon balance is influenced by temperate and boreal floras as they will remain a large sink of anthropogenic carbon dioxide. Some soil bacteria are capable of fixing $\mathrm{CO}_{2}$ in the soil. Bradyrhizobium (Betaproteobacteria) is a bacterium that inhabits forest soils in large numbers [106]. For forest soils with aerobic conditions, methane represents a gaseous form of organic carbon [107]. It has been reported that these methanotrophs are the primary consumers of atmospheric methane as well as methane from waterlogged, anaerobic soil horizons [108]. Methane can be sequestered from the atmosphere by forest soils (especially those of boreal forests) because of the presence of methanotrophic bacteria. Most of the characterized methanotrophs belong to the Alphaproteobacteria and Gammaproteobacteria[109].

In unmanaged environments, bacteria are estimated to contribute more than $95 \%$ of the $\mathrm{N}$ input [101].nifH is present in the Alphaproteobacteria (Bradyrhizobium, Azospirillum, Hyphomicrobium, and Gluconacetobacterspecies) and Deltaproteobacteria (Geobacterspecies). was observed in different temperate forest soils, demonstrating the ubiquity of some $\mathrm{N}$-fixing bacteria, not only as symbiotic but also as free-living taxa [106].

\section{CONCLUSION}

The PGPR bacteria are beneficial bacteria that colonize the roots of plants and enhance their growth through a variety of mechanisms. In similar geographical locations, the soil, rhizosphere, phyllosphere and associated bacterial communities are similar, whereas plants in distant geographic locations with distinct soil properties have a different soil bacterial community and have different associated bacterial communities. Soil environment and geophysical conditions have a direct impact on bacterial diversity. The functional profiles of soil bacterial communities were influenced by both the location of the soil and the plants in the soil.

\section{ACKNOWLEDGEMENTS}

We express our gratitude to Dr. Atreyi Ghosh, Dr. Somsubhra Thakur Choudhury, Dr. Fatema Calcuttawala and Dr. Argha Chakraborty for their help and cooperation throughout this study. We are also thankful to Sister Nivedita University start up grant for supporting this work.

\section{REFERENCES}

[1] O'Brien, Flora JM, et al. "Rhizosphere bacterial communities differ according to fertilizer regimes and 
cabbage (Brassica oleracea var. capitata L.) harvest time, but not aphid herbivory." Frontiers in microbiology 9 (2018): 1620.

[2] Lundberg, Derek S., et al. "Defining the core Arabidopsis thaliana root microbiome." Nature 488.7409 (2012): 86-90.

[3] Edwards, Joseph, et al. "Structure, variation, and assembly of the root-associated microbiomes of rice." Proceedings of the National Academy of Sciences 112.8 (2015): E911E920.

[4] Glick, Bernard R. "Plant growth-promoting bacteria: mechanisms and applications." Scientifica 2012 (2012)

[5] Boyetchko, Susan M., and Antonet M. Svircev. "A novel approach for developing microbial biopesticides." Biological Control Programmes in Canada 2001-2012 (2013): 37-43.

[6] Glick, Bernard R. "The enhancement of plant growth by free-living bacteria." Canadian journal of microbiology 41.2 (1995): 109-117.

[7] Etesami, Hassan, and Gwyn A. Beattie. "Plant-microbe interactions in adaptation of agricultural crops to abiotic stress conditions." Probiotics and Plant Health. Springer, Singapore, 2017. 163-200.

[8] Etesami, Hassan, and Dinesh K. Maheshwari. "Use of plant growth promoting rhizobacteria (PGPRs) with multiple plant growth promoting traits in stress agriculture: Action mechanisms and future prospects." Ecotoxicology and environmental safety 156 (2018): 225-246.

[9] Yang, Xiyan, and Xianlong Zhang. "Regulation of somatic embryogenesis in higher plants." Critical Reviews in Plant Science 29.1 (2010): 36-57.

[10] Martínez-Viveros, O., et al. "Mechanisms and practical considerations involved in plant growth promotion by rhizobacteria." Journal of soil science and plant nutrition 10.3 (2010): 293-319.

[11] Bhattacharyya, P. N., and Jha, D. K. (2012). Plant growthpromoting rhizobacteria (PGPR): emergence in agriculture. World J. Microbiol. Biotechnol. 28, 1327-1350. doi: 10.1007/s11274-011-0979-9

[12] Vessey, J. Kevin. "Plant growth promoting rhizobacteria as biofertilizers." Plant and soil 255.2 (2003): 571-586.

[13] Gray, E. J., and D. L. Smith. "Intracellular and extracellular PGPR: commonalities and distinctions in the plant-bacterium signaling processes." Soil biology and biochemistry 37.3 (2005): 395-412.

[14] Khan, N., Bano, A., Ali, S., and Babar, M. A. (2020). Crosstalk amongst phytohormones from planta and PGPR under biotic and abiotic stresses. Plant Growth Regul. 90, 189-203. doi: 10.1007/s10725-020-00571-x

[15] Hartmann, A., Rothballer, M., Hense, B. A., and Schröder, P. (2014). Bacterial quorum sensing compounds are important modulators of microbe-plant interactions. Front. Plant Sci. 5:131. doi: 10.3389/fpls.2014.00131

[16] Rutherford, S. T., and Bassler, B. L. (2012). Bacterial quorum sensing: its role in virulence and possibilities for its control. Cold Spring Harb. Perspect. Med. 2:a012427. doi: 10.1101/cshperspect.a012427
[17] Altaf, M. M., Khan, M. S. A., Abulreesh, H. H., and Ahmad, I. (2017). "Quorum sensing in plant growthpromoting Rhizobacteria and its impact on plant-microbe interaction," in Plant-Microbe Interactions in AgroEcological Perspectives: Volume 1: Fundamental Mechanisms, Methods and Functions, eds D. P. Singh, H. B. Singh, and R. Prabha (Singapore: Springer), 311-331. doi: 10.1007/978-981-10-5813-4_16

[18] Elasri, Miena, et al. "Acyl-homoserine lactone production is more common among plant-associated Pseudomonas spp. than among soilborne Pseudomonas spp." Applied and environmental microbiology 67.3 (2001): 1198-1209.

[19] Quadt-Hallmann, A. N. D. R. E. A., J. W. Kloepper, and N. Benhamou. "Bacterial endophytes in cotton: mechanisms of entering the plant." Canadian journal of microbiology 43.6 (1997): 577-582.

[20] Lodewyckx, Cindy, et al. "Endophytic bacteria and their potential applications." Critical reviews in plant sciences 21.6 (2002): 583-606.

[21] Berg, G., and Smalla, K. (2009). Plant species and soil type cooperatively shape the structure and function of microbial communities in the rhizosphere. FEMS Microbiol. Ecol. 68, 1-13. doi: 10.1111/j.1574-6941.2009.00654.x

[22] Vejan, Pravin, et al. "Role of plant growth promoting rhizobacteria in agricultural sustainability-a review." Molecules 21.5 (2016): 573.

[23] Marasco, R., Mosqueira, M. J., Fusi, M., Ramond, J.-B., Merlino, G., Booth, J. M., et al. (2018). Rhizosheath microbial community assembly of sympatric desert speargrasses is independent of the plant host. Microbiome 6:215. doi: 10.1186/s40168-018-0597-y

[24] Bechtold, Ulrike. "Plant life in extreme environments: how do you improve drought tolerance?." Frontiers in plant science 9 (2018): 543.

[25] Hsiao, Theodore C., and Liu-Kang Xu. "Sensitivity of growth of roots versus leaves to water stress: biophysical analysis and relation to water transport." Journal of experimental botany 51.350 (2000): 1595-1616.

[26] Vurukonda, Sai Shiva Krishna Prasad, et al. "Enhancement of drought stress tolerance in crops by plant growth promoting rhizobacteria." Microbiological research 184 (2016): 13-24.

[27] Gill, Sarvajeet Singh, and Narendra Tuteja. "Reactive oxygen species and antioxidant machinery in abiotic stress tolerance in crop plants." Plant physiology and biochemistry 48.12 (2010): 909-930.

[28] Hou, Lin, et al. "Smart nanocomposite hydrogels based on azo crosslinked graphene oxide for oral colon-specific drug delivery." Nanotechnology 27.31 (2016): 315105.

[29] Mohammadi, Mohammad Hossein Sheikh, et al. "Molecular and physiological responses of Iranian Perennial ryegrass as affected by Trinexapac ethyl, Paclobutrazol and Abscisic acid under drought stress." Plant Physiology and Biochemistry 111 (2017): 129-143.

[30] Xie, Xiulan, et al. "The roles of environmental factors in regulation of oxidative stress in plant." BioMed research international 2019 (2019). 
[31] Hinojosa, Leonardo, Janet B. Matanguihan, and Kevin M. Murphy. "Effect of high temperature on pollen morphology, plant growth and seed yield in quinoa (Chenopodium quinoa Willd.)." Journal of agronomy and crop science 205.1 (2019): 33-45.

[32] Paul, D., and Lade, H. (2014). Plant-growth-promoting rhizobacteria to improve crop growth in saline soils: a review. Agron. Sustain. Dev. 34, 737-752. doi: 10.1007/s13593-014-0233-6

[33] Makhalanyane, Thulani P., et al. "Microbial ecology of hot desert edaphic systems." FEMS microbiology reviews 39.2 (2015): 203-221.

[34] Eida, A. A., Ziegler, M., Lafi, F. F., Michell, C. T., Voolstra, C. R., Hirt, H., et al. (2018). Desert plant bacteria reveal host influence and beneficial plant growth properties. PLoS One 13:e0208223. doi: 10.1371/journal.pone.0208223

[35] Bokhari, A., Essack, M., Lafi, F. F., Andres-Barrao, C., Jalal, R., Alamoudi, S., et al. (2019). Bioprospecting desert plant Bacillus endophytic strains for their potential to enhance plant stress tolerance. Sci. Rep. 9:18154. doi: 10.1038/s41598-019-54685-y

[36] Eida, A. A., Alzubaidy, H. S., de Zélicourt, A., Synek, L., Alsharif, W., Lafi, F. F., et al. (2019). Phylogenetically diverse endophytic bacteria from desert plants induce transcriptional changes of tissue-specific ion transporters and salinity stress in Arabidopsis thaliana. Plant Sci. 280, 228-240. doi: 10.1016/j.plantsci.2018.12.002

[37] Pini, F., Galardini, M., Bazzicalupo, M., and Mengoni, A. (2011). Plant-bacteria association and symbiosis: are there common genomic traits in alphaproteobacteria? Genes 2, 1017-1032. doi: 10.3390/genes2041017

[38] Mohammadipanah, F., and Wink, J. (2016). Actinobacteria from arid and desert habitats: diversity and biological activity. Front. Microbiol. 6:1541. doi: 10.3389/fmicb.2015.01541

[39] Ramawat, K. G. (2010). Desert Plants Biology and Biotechnology. Berlin: Springer.

[40] Fierer, N., Leff, J. W., Adams, B. J., Nielsen, U. N., Bates, S. T., Lauber, C. L., et al. (2012). Cross-biome metagenomic analyses of soil microbial communities and their functional attributes. Proc. Natl. Acad. Sci. U.S.A. 109:21390. doi: 10.1073/pnas.1215210110

[41] Hacquard, S., Garrido-Oter, R., González, A., Spaepen, S., Ackermann, G., Lebeis, S., et al. (2015). Microbiota and host nutrition across plant and animal kingdoms. Cell Host Microbe 17, 603-616. doi: 10.1016/j.chom.2015.04.009

[42] Saad, Maged M., Abdul Aziz Eida, and Heribert Hirt. "Tailoring plant-associated microbial inoculants in agriculture: a roadmap for successful application." Journal of experimental botany 71.13 (2020): 3878-390.

[43] Belimov, Andrey A., et al. "Rhizosphere bacteria containing 1-aminocyclopropane-1-carboxylate deaminase increase yield of plants grown in drying soil via both local and systemic hormone signalling." New Phytologist 181.2 (2009): 413-423.
[44] Zhang, Min, et al. "Drought-tolerant plant growthpromoting rhizobacteria isolated from jujube (Ziziphus jujuba) and their potential to enhance drought tolerance." Plant and Soil 452.1 (2020): 423-440.

[45] Huang, Chao, et al. "Effect of Phanerochaetechrysosporium inoculation on bacterial community and metal stabilization in lead-contaminated agricultural waste composting." Bioresource technology 243 (2017): 294-303.

[46] Chandra, Rohan, et al. "Robusttp: End-to-end trajectory prediction for heterogeneous road-agents in dense traffic with noisy sensor inputs." ACM Computer Science in Cars Symposium. 2019.

[47] Kim, Jungmin, et al. "Methods of downstream processing for the production of biodiesel from microalgae." Biotechnology advances 31.6 (2013): 862-876.

[48] Sandhya, V. S. K. Z., et al. "Effect of plant growth promoting Pseudomonas spp. on compatible solutes, antioxidant status and plant growth of maize under drought stress." Plant Growth Regulation 62.1 (2010): 21-30.

[49] Naseem, Hafsa, and AsghariBano. "Role of plant growthpromoting rhizobacteria and their exopolysaccharide in drought tolerance of maize." Journal of Plant Interactions 9.1 (2014): 689-701.

[50] Alsharif, Mohammed H., et al. "Sixth generation (6G) wireless networks: Vision, research activities, challenges and potential solutions." Symmetry 12.4 (2020): 676.

[51] Ribeiro, ViníciusErlo, et al. "Enhanced essential oil and leaf anatomy of Schinusmolle plants under lead contamination." Industrial Crops and Products 132 (2019): 92-98.

[52] Saleh, Dina, et al. "Diversity, distribution and multi-functional attributes of bacterial communities associated with the rhizosphere and endosphere of timothy (Phleum pratense L.)." Journal of applied microbiology 127.3 (2019): 794-811.

[53] Saleem, Muhammad, et al. "Perspective of plant growth promoting rhizobacteria (PGPR) containing ACC deaminase in stress agriculture." Journal of Industrial Microbiology and Biotechnology 34.10 (2007): 635-648.

[54] Pérez-Montaño, F., et al. "Plant growth promotion in cereal and leguminous agricultural important plants: from microorganism capacities to crop production." Microbiological research 169.5-6 (2014): 325-336.

[55] Wang, Chuan, et al. "Plant growth-promoting rhizobacteria isolation from rhizosphere of submerged macrophytes and their growth-promoting effect on Vallisneria natans under high sediment organic matter load." Microbial Biotechnology 14.2 (2021): 726-736.

[56] Ho, PooiLeng, et al. "HEXIM1 peptide exhibits antimicrobial activity against antibiotic resistant bacteria through guidance of cell penetrating peptide." Frontiers in microbiology 10 (2019): 203.

[57] Sand-Jensen, Kaj, et al. "100 years of vegetation decline and recovery in Lake Fure, Denmark." Journal of Ecology 96.2 (2008): 260-271. 
[58] Wu, Shan Shan. Enhanced phytoremediation of saltimpacted soils using plant growth-promoting rhizobacteria (PGPR). MS thesis. University of Waterloo, 2009.

[59] Soana, Elisa, et al. "Benthic nitrogen metabolism in a macrophyte meadow (Vallisneria spiralis L.) under increasing sedimentary organic matter loads." Biogeochemistry 124.1 (2015): 387-404.

[60] Phillips, M., Adrian Lee, and W. D. Leach. "The mucosa-associated microflora of the rat intestine: a study of normal distribution and magnesium sulphate induced diarrhoea." Australian Journal of Experimental Biology and Medical Science 56.6 (1978): 649-662.

[61] Upadhyay, Sudhir Kumar, et al. "Impact of PGPR inoculation on growth and antioxidant status of wheat under saline conditions." Plant Biology 14.4 (2012): 605611.

[62] Zhu, Fengling, et al. "Isolation and characterization of a phosphate-solubilizing halophilic bacterium Kushneria sp. YCWA18 from Daqiao Saltern on the coast of Yellow Sea of China." Evidence-Based Complementary and Alternative Medicine 2011 (2011).

[63] Flowers, Timothy J., and Timothy D. Colmer. "Salinity tolerance in halophytes." New Phytologist 179.4 (2008): 945-963.

[64] Kumari, Baby, et al. "Plant growth promoting rhizobacteria (PGPR): modern prospects for sustainable agriculture." Plant health under biotic stress. Springer, Singapore, 2019. 109-127.

[65] Jha, Yachana, and R. B. Subramanian. "Paddy plants inoculated with PGPR show better growth physiology and nutrient content under saline condition." Chilean journal of agricultural research 73.3 (2013): 213-219

[66] Jha, Chaitanya Kumar, and Meenu Saraf. "Plant growth promoting rhizobacteria (PGPR)." JOURNAL OF AGRICULTURE RESEARCH AND DEVELOPMENT 5.2 (2015): 0108-0119.

[67] Shukla, Arvind K., et al. "Micronutrients and field crop production in India: a review." Indian Journal of Agronomy 57.3s (2012): 123-130.

[68] Nabti, Elhafid, Michael Schmid, and Anton Hartmann. "Application of halotolerant bacteria to restore plant growth under salt stress." Halophiles. Springer, Cham, 2015. 235-259.

[69] Sharma, Sandeep, Jayant Kulkarni, and Bhavanath Jha. "Halotolerant rhizobacteria promote growth and enhance salinity tolerance in peanut." Frontiers in microbiology 7 (2016): 1600.

[70] Rohban, R., Mohammad Ali Amoozegar, and A. Ventosa. "Screening and isolation of halophilic bacteria producing extracellular hydrolyses from HowzSoltan Lake, Iran." Journal of Industrial Microbiology and Biotechnology 36.3 (2009): 333-340.

[71] Siddikee, Md Ashaduzzaman, et al. "Isolation, characterization, and use for plant growth promotion under salt stress, of ACC deaminase-producing halotolerant bacteria derived from coastal soil." Journal of Microbiology and Biotechnology 20.11 (2010): 1577-1584.
[72] Bharti, Nidhi, et al. "Exiguobacteriumoxidotolerans, a halotolerant plant growth promoting rhizobacteria, improves yield and content of secondary metabolites in Bacopa monnieri (L.) Pennell under primary and secondary salt stress." World Journal of Microbiology and Biotechnology 29.2 (2013): 379-387.

[73] Larsen, Helge. "Halophilic and halotolerant microorganisms - an overview and historical perspective." (1986): 3-7.

[74] Khan, Naeem, and AsghariBano. "Modulation of phytoremediation and plant growth by the treatment with PGPR, Ag nanoparticle and untreated municipal wastewater." International journal of phytoremediation 18.12 (2016): 1258-1269.

[75] Ruppel, Silke, Philipp Franken, and Katja Witzel. "Properties of the halophyte microbiome and their implications for plant salt tolerance." Functional Plant Biology 40.9 (2013): 940-951.

[76] Bottini, Rubén, Fabricio Cassán, and Patricia Piccoli. "Gibberellin production by bacteria and its involvement in plant growth promotion and yield increase." Applied microbiology and biotechnology 65.5 (2004): 497-503.

[77] Kang, Sang-Mo, et al. "Plant growth-promoting rhizobacteria reduce adverse effects of salinity and osmotic stress by regulating phytohormones and antioxidants in Cucumis sativus." Journal of Plant Interactions 9.1 (2014): 673-682.

[78] Shahzad, Raheem, et al. "Plant growth-promoting endophytic bacteria versus pathogenic infections: an example of Bacillus amyloliquefaciens RWL-1 and Fusarium oxysporum f. sp. lycopersici in tomato." PeerJ 5 (2017): e3107.

[79] Magome, Hiroshi, and Yuji Kamiya. "Inactivation processes." Annu. Plant Rev 49 (2016): 73-94.

[80] Martínez, Oscar A., et al. "Serratia strains isolated from the rhizosphere of raulí (Nothofagusalpina) in volcanic soils harbour PGPR mechanisms and promote raulí plantlet growth." Journal of soil science and plant nutrition 18.3 (2018): 804-819.

[81] Guo, J. H., et al. "The plant healthy and safety guards plant growth promoting rhizo bacteria (PGPR)." Transcriptomics 3.109 (2015): 2.

[82] Wang, Xuefei, et al. "Biocontrol and plant growth-promoting activity of rhizobacteria from $\mathrm{C}$ hinese fields with contaminated soils." Microbial biotechnology 8.3 (2015): 404-418.

[83] Sengupta, Anjan, and Subhendu Chaudhuri. "Ecology of heterotrophic dinitrogen fixation in the rhizosphere of mangrove plant community at the Ganges river estuary in India." Oecologia 87.4 (1991): 560-564.

[84] Holguin, Gina, M. Antonia Guzman, and Yoav Bashan. "Two new nitrogen-fixing bacteria from the rhizosphere of mangrove trees: Their isolation, identification and in vitro interaction with rhizosphere Staphylococcus sp." FEMS Microbiology Letters 101.3 (1992): 207-216. 
[85] Alongi DM, Christoffersen P, Tirendi F (1993) The influence of forest type on microbial-nutrient relationships in tropical mangrove sediments. J Exp Mar BiolEcol 171:201-223

[86] Holguin, G., C. L. Patten, and B. R. Glick. "Genetics and molecular biology of Azospirillum." Biology and fertility of soils 29.1 (1999): 10-23.

[87] Holguin, Gina, Patricia Vazquez, and Yoav Bashan. "The role of sediment microorganisms in the productivity, conservation, and rehabilitation of mangrove ecosystems: an overview." Biology and fertility of soils 33.4 (2001): 265-278.

[88] Kathiresan, Kandasamy, and Brian L. Bingham. "Biology of mangroves and mangrove ecosystems." (2001): 81-251.

[89] Toledo-Aral, Juan José, et al. "A single pulse of nerve growth factor triggers long-term neuronal excitability through sodium channel gene induction." Neuron 14.3 (1995): 607-611.

[90] Bashan, Yoav. "Inoculants of plant growth-promoting bacteria for use in agriculture." Biotechnology advances 16.4 (1998): 729-770.

[91] Rojas, Gabriela, et al. "Antimicrobial evaluation of certain plants used in Mexican traditional medicine for the treatment of respiratory diseases." Journal of Ethnopharmacology 74.1 (2001): 97-101.

[92] Gotto, John W., and Barrie F. Taylor. "N2 fixation associated with decaying leaves of the red mangrove (Rhizophora mangle)." Applied and Environmental Microbiology 31.5 (1976): 781-783.

[93] Zuberer, D_A, and WS242881 Silver. "Biological dinitrogen fixation (acetylene reduction) associated with Florida mangroves." Applied and environmental Microbiology 35.3 (1978): 567-575.

[94] Zuberer, D. A., and W. S. Silver. "N2-Fixation (acetylene reduction) and the microbial colonization of mangrove roots." New Phytologist 82.2 (1979): 467-471.

[95] Pots, Bernardus Franciscus Maria. "Turbulence and transport in a magnetized argon plasma." (1979)

[96] Uchino, Fuji, Gregori G. Hambali, and Michihiko Yatazawa. "Nitrogen-fixing bacteria from warty lenticellate bark of a mangrove tree, Bruguieragymnorrhiza (L.) Lamk." Applied and environmental microbiology 47.1 (1984): 44-48.

[97] Van der Valk, A. G., and P. M. Attiwill. "Acetylene reduction in an Avicennia marina community in Southern Australia." Australian journal of botany 32.2 (1984): 157 164.

[98] Hicks, Brendan J., and Warwick B. Silvester. "Nitrogen fixation associated with the New Zealand mangrove (Avicennia marina (Forsk.) Vierh. var. resinifera (Forst. f.) Bakh.)." Applied and environmental microbiology 49.4 (1985): 955-959.

[99] Mann, Fiona D., and T. D. Steinke. "Biological nitrogen fixation (acetylene reduction) associated with decomposing Avicennia marina leaves in the Beachwood Mangrove
Nature Reserve." South African Journal of Botany 58.6 (1992): 533-536.

[100] Sengupta, A., and S. Chaudhuri. "Vesicular arbuscular mycorrhiza (VAM) in pioneer salt marsh plants of the Ganges river delta in West Bengal (India)." Plant and Soil 122.1 (1990): 111-113.

[101] Reed, Sasha C., Cory C. Cleveland, and Alan R. Townsend. "Functional ecology of free-living nitrogen fixation: a contemporary perspective." Annual review of ecology, evolution, and systematics 42 (2011): 489-512.

[102] Uroz, Stéphane, et al. "Bacterial weathering and its contribution to nutrient cycling in temperate forest ecosystems." Research in microbiology 162.9 (2011): 820831.

[103] Hardoim, P. R. "Heading to the origins-Rice microbiome as functional extension of the host." Journal of Rice Research 3.2 (2015): 1-3.

[104] Lauber, Christian L., et al. "Temporal variability in soil microbial communities across land-use types." The ISME journal 7.8 (2013): 1641-1650.

[105] Xia, Ye, et al. "Multi-stress tolerant PGPR Bacillus xiamenensis PM14 activating sugarcane (Saccharum officinarum L.) red rot disease resistance." Plant Physiology and Biochemistry 151 (2020): 640-649.

[106] VanInsberghe, David, et al. "Non-symbiotic Bradyrhizobium ecotypes dominate North American forest soils." The ISME journal 9.11 (2015): 2435-2441.

[107] Lau, EeTiing, Choy Yuen Khew, and Siaw San Hwang. "Transcriptomic analysis of pepper plants provides insights into host responses to Fusarium solani infestation." Journal of biotechnology 314 (2020): 53-62.

[108] Savi, D.C., Aluizio, R., Galli-Terasawa, L. et al. 16S-gyrBrpoB multilocus sequence analysis for species identification in the genus Microbispora. Antonie van Leeuwenhoek 109, 801-815 (2016). https://doi.org/10.1007/s10482-016-0680-y

[109] Esson, Kaitlin C., et al. "Alpha-and gammaproteobacterial methanotrophs codominate the active methane-oxidizing communities in an acidic boreal peat bog." Applied and environmental microbiology 82.8 (2016): 2363-2371. 